\title{
Inhibiting TrxR suppresses liver cancer by inducing apoptosis and eliciting potent antitumor immunity
}

\author{
HONG LEI, GUAN WANG, JIAN ZHANG and QIUJU HAN \\ Institute of Immunopharmaceutical Sciences, School of Pharmaceutical Sciences, \\ Shandong University, Jinan, Shandong 250012, P.R. China
}

Received March 29, 2018; Accepted September 20, 2018

DOI: 10.3892/or.2018.6740

\begin{abstract}
Liver cancer is one of the most common malignant tumors worldwide. Thioredoxin reductase ( $\operatorname{Tr} \mathrm{R})$ is highly expressed in liver cancer cells. The present study aimed to investigate the effect of inhibiting Trx R on liver cancer and to better understand the underlying molecular and immunological mechanisms associated with inhibition. It was demonstrated that targeting TrxR inhibited the growth and induced apoptosis of liver cancer cells, which was accompanied by activation of the mitogen associated protein kinase pathway. This inhibition was dependent on the production of reactive oxygen species (ROS). Blockage of ROS production reversed TrxR inhibitor-induced antitumor effects. Blocking the Trx/TrxR system activated the mammalian target of rapamycin pathway and inhibited autophagy, which occurred in a ROS-independent manner. TrxR inhibition led to lesions in the mitochondrial membrane, indicated by alterations in membrane potential. Mouse xenograft experiments were highly consistent with in vitro studies. Most importantly, blocking the Trx/TrxR system improved the tumor immune microenvironment. Together, these data demonstrated that TrxR is a potential target for liver cancer therapy, which could inhibit hepatocarcinogenesis and progression, and improve the antitumor immune response.
\end{abstract}

\section{Introduction}

Liver cancer, including hepatocellular carcinoma (HCC) and cholangiocarcinoma in adults, and hepatoblastoma mainly in children, is one of the most common malignant tumors and is the most frequent cause of cancer-associated death worldwide (1). Much progress has been made in liver cancer

Correspondence to: Dr Qiuju Han, Institute of Immunopharmaceutical Sciences, School of Pharmaceutical Sciences, Shandong University, 44 Wenhua West Road, Jinan, Shandong 250012, P.R. China

E-mail: hanqiuju@sdu.edu.cn

Key words: liver cancer, thioredoxin reductase inhibitor, reactive oxygen species, tumor immunology, autophagy research and current options for the treatment of the early stage liver cancer include radio frequency ablation, hepatic resection and transplantation (2,3). Unfortunately, $>50 \%$ of HCC cases are diagnosed at an intermediate or advanced tumor stage (4). Oral administration of sorafenib, a small molecule multikinase inhibitor, is currently the only treatment that substantially prolongs survival in patients with advanced HCC, making sorafenib the standard treatment for advanced stage HCC. Although sorafenib treatment improves survival among patients with advanced HCC, toxicity and unsatisfactory antitumor effects remain unsolved issues with this drug $(5,6)$. Although novel molecular targeting agents including regorafenib have been approved, none of the inhibitors have demonstrated satisfactory results. Therefore, there remains a need for improved therapeutics for liver cancer.

Thioredoxin $(\operatorname{Tr} x)$ and thioredoxin reductase $(\operatorname{Tr} x \mathrm{R})$ provide a coupled redox system, which serves key roles in maintaining redox reactions in biosynthetic pathways and controlling redox homeostasis in cells. Trx, a redox regulatory protein, can be oxidized by abundant reactive oxygen species (ROS). TrxR reactivates Trx by reduction, providing a circuit for sequential turnover in multiple oxidation/reduction cycles (7).

It has been suggested that TrxR serves important roles in diverse physiological and pathological processes, including apoptosis, cancer, chronic inflammation, autoimmune diseases and neurodegenerative disorders (7). In previous years, several studies have reported that $\operatorname{Trx}$ or TrxR are overexpressed in tumors including lung, breast, colorectal, pancreatic, hepatocellular, gastric, myeloma, non-Hodgkin lymphoma and acute lymphocytic leukemia $(8,9)$. TrxR contributes to tumor growth through the hypoxia inducible factor-1 pathway and is essential to maintain tumor phenotypes and metastasis $(10,11)$. Accumulating evidence indicates that $\operatorname{Trx} R / \operatorname{Trx}$ is an important modulator of tumor development. Therefore, targeting $\operatorname{TrxR} / \operatorname{Trx}$ is a promising strategy for cancer treatment $(8,12)$.

Due to its involvement in pathological processes, inhibiting TrxR is an important clinical goal. Recently, several studies have described inhibitors of TrxR, for example, gold (I) N-heterocyclic carbene complexes, that exhibit clear and strong anti-proliferative effects on a wide range of tumor cells (13). Generally, TrxR inhibitors display antitumor effects by promoting the apoptosis of tumor cells $(8,9,14)$. TrxR expression has been demonstrated to be associated with liver 
cancer $(15,16)$; however, whether TrxR can serve as a therapeutic target for liver cancer has yet to be determined.

In the present study, whether blocking TrxR using the inhibitor chloro(triethylphosphine)gold(I) (AA1), could inhibit the growth of liver cancer cells in vitro and in vivo was examined. Targeting TrxR resulted in the production of ROS, the inhibition of autophagy and the induction of lesions in the mitochondrial membranes in liver cancer cells. Additionally, AA1 induced a profound antitumor immune response in the tumor immune microenvironment.

\section{Materials and methods}

Cell culture and reagents. Human liver cancer cell line HepG2 (17), the C57BL/6-derived hepatoma cell line Hepa1-6, MDA-MB231, Hela, B16, K562, HL-60, A549, H7402, PLC and HepG2.2.15 cells were purchased from the Cell Bank of Type Culture Collection of the Chinese Academy of Sciences (Shanghai, China). Cells were cultured in Dulbecco's modified Eagle's medium (Thermo Fisher Scientific, Inc., Waltham, MA, USA) supplemented with $10 \%$ fetal bovine serum (Sijiqing; Zhejiang Tianhang Biotechnology Co., Ltd., Hangzhou, China) at $37^{\circ} \mathrm{C}$ with $5 \% \mathrm{CO}_{2}$. AA1, a potent TrxR inhibitor, was kindly provided by Professor Minyong Li at the School of Pharmaceutical Sciences, Shandong University (Shandong, China) (18). Cisplatin was obtained from Sigma-Aldrich (Merck KGaA, Darmstadt, Germany), and was dissolved in $0.9 \% \mathrm{NACl}$ at a final concentration of $100 \mathrm{mg} / \mathrm{ml}$.

Animal models. 6-week-old male nude mice ( $\mathrm{n}=6,19-21 \mathrm{~g})$ and C57BL/6 mice ( $\mathrm{n}=7,21-23 \mathrm{~g})$ were purchased from Beijing HFK Bioscience Co., Ltd., (Beijing, China) and maintained under specific pathogen-free conditions (temperature $25^{\circ} \mathrm{C}$, relative humidity $45 \%$ ) with a 12 -h light-dark cycle. A total of $2 \times 10^{6}$ Hepa1-6 cells in $200 \mu$ l PBS were injected into nude mice or C57BL/6 mice and seven days later, AA1 ( $2 \mathrm{mg} / \mathrm{kg})$ or PBS as a control was intraperitoneally injected into tumor-bearing mice every two days for seven total injections. Cisplatin ( $3 \mathrm{mg} / \mathrm{kg}$ ) was as a positive control in tumor-bearing nude mice. Tumor volumes were determined by measuring length (l) and width (w) at the indicated time points. At the end of treatment, the mice were sacrificed and the tumors removed and used for ROS and tumor immune environment evaluation. All animals were kept in standard laboratory conditions and provided with food and water ad libitum. The animal experiments were approved by the Research Ethics Committee of Shandong University.

TrxR activity analysis by 3-carboxy-4-nitrophenyl disulfide (DNTB) assay. HepG2 or Hepa1-6 cells were incubated with different concentrations of AA1 for $48 \mathrm{~h}$. Cells were harvested and cell lysates were prepared with a RIPA lysis buffer (Beyotime Institute of Biotechnology, Shanghai, China) in the presence of protease inhibitors. Protein concentration of the supernatant was determined using the Bradford reagent. A total of $25 \mu \mathrm{g}$ of extract were incubated with $1 \mathrm{mM}$ NADPH and $2 \mathrm{mM}$ selenocystine (SC) in Tris EDTA buffer [50 $\mathrm{mM}$ Tris- $\mathrm{HCl}$ and $2 \mathrm{mM}$ EDTA, $(\mathrm{pH}$ 7.5)] in a total volume of $100 \mu \mathrm{l}$. Samples of protein only, protein and NADPH, and protein and SC were used as controls. The reaction mixture was placed into 96-well microplates and monitored at $30 \mathrm{sec}$ intervals over a 20 min period, and the absorbance was measured at $412 \mathrm{~nm}$ (BioRad Laboratories, Inc., Hercules, CA, USA) (9).

Cell viability assay. HepG2 and Hepa1-6 cells $\left(4 \times 10^{3}\right)$ were seeded in 96-well plates, then HepG2 were treated with AA1 $(1.25,2.5,5$ and $10 \mu \mathrm{M})$, and Hep1-6 cells were treated with AA1 $(0.3,0.6,1.25,2.5$ and $5 \mu \mathrm{M})$ at the indicated time points (24 and $48 \mathrm{~h}$ ), then MTT assays performed to measure the inhibitory effects of AA1 on the proliferation of liver cancer cell. At last, DMSO was used to dissolve the purple formazan, and the absorbance of the plate was measured at $490 \mathrm{~nm}$.

Cell cycle analysis and apoptosis assay. HepG2 cells $\left(1.5 \times 10^{5}\right)$ were seeded in 12-well plates. The following day, cells were treated with AA1 at the indicated concentrations $(2.5,5$ and $10 \mu \mathrm{M})$. Following $24 \mathrm{~h}$, cells were harvested, washed twice with ice-cold PBS and fixed in $70 \%$ ethanol at $4^{\circ} \mathrm{C}$ overnight. Cells were then washed once with ice-cold PBS and re-suspended in $1 \mathrm{ml}$ of staining reagent containing $50 \mathrm{mg} / \mathrm{ml}$ propidium iodide (PI) and $100 \mathrm{mg} / \mathrm{ml} \mathrm{RNase.} \mathrm{Cells} \mathrm{were} \mathrm{incubated} \mathrm{for} 30 \mathrm{~min}$ in the dark, then cell cycle analysis was performed using a flow cytometer (BD FACS Calibur; BD Biosciences, Franklin Lakes, NJ, USA) (19). To determine rates of apoptosis, cells underwent the same treatment and analysis as for cell cycle analysis but were stained with Annexin V-fluorescein isothiocyanate (FITC)/PI (eBioscience; Thermo Fisher Scientific, Inc.), according to the manufacturer's protocol. The data were analyzed using WinMDI version 2.8 software (The Scripps Research Institute, La Jolla, CA, USA).

Evaluation of mitochondrial membrane potential (MMP). HepG2 and Hepa1-6 cells $\left(1 \times 10^{5}\right)$ were seeded in $60 \mathrm{~mm}$ cell culture dishes. Then, HepG2 cells were treated with 2.5 and $5 \mu \mathrm{M}$, Hep1-6 cells were treated with 1.25 and $2.5 \mu \mathrm{M}, 48 \mathrm{~h}$ later, cells were harvested and washed twice with ice-cold PBS, then incubated with JC-1 (10 $\mu \mathrm{g} / \mathrm{ml}$; cat. no. C2006; Beyotime Institute of Biotechnology) in the dark for $15 \mathrm{~min}$ at $37^{\circ} \mathrm{C}$. Cells were washed three times with ice-cold PBS and analyzed by fluorescence microscopy (Olympus Corporation, Tokyo, Japan) using emission wavelengths of 590 and $525 \mathrm{~nm}$.

Determination of ROS production. HepG2 and Hepa1-6 cells $\left(1.5 \times 10^{5}\right)$ were seeded in $60-\mathrm{mm}$ cell culture dishes. Following treatment with AA1 for $6 \mathrm{~h}$, cells were incubated with $10 \mu \mathrm{M}$ 2',7'-dichlorofluorescein diacetate (DCFH-DA; cat. no. D6883; Sigma-Aldrich; Merck KGaA) for $15 \mathrm{~min}$ in the dark, washed three times with ice-cold PBS and the ROS levels analyzed by fluorescence microscopy (Olympus Corporation) (20).

Nuclear staining. HepG2 and Hepa1-6 cells $\left(1.5 \times 10^{5}\right)$ were seeded in $60-\mathrm{mm}$ cell culture dishes. Following treatment for $12 \mathrm{~h}$, cells were harvested and washed three times with cold PBS, following which cells were fixed with $4 \%$ polyoxymethylene for $10 \mathrm{~min}$ at room temperature. Then, cells were rinsed with PBS, and incubated with $1 \mu \mathrm{M}$ DAPI (cat. no. C1002; Beyotime Institute of Biotechnology) for $10 \mathrm{~min}$ at $37^{\circ} \mathrm{C}$ in dark. Then, the cells were imaged using a fluorescent microscope (CK30-F200; Olympus Corporation). 

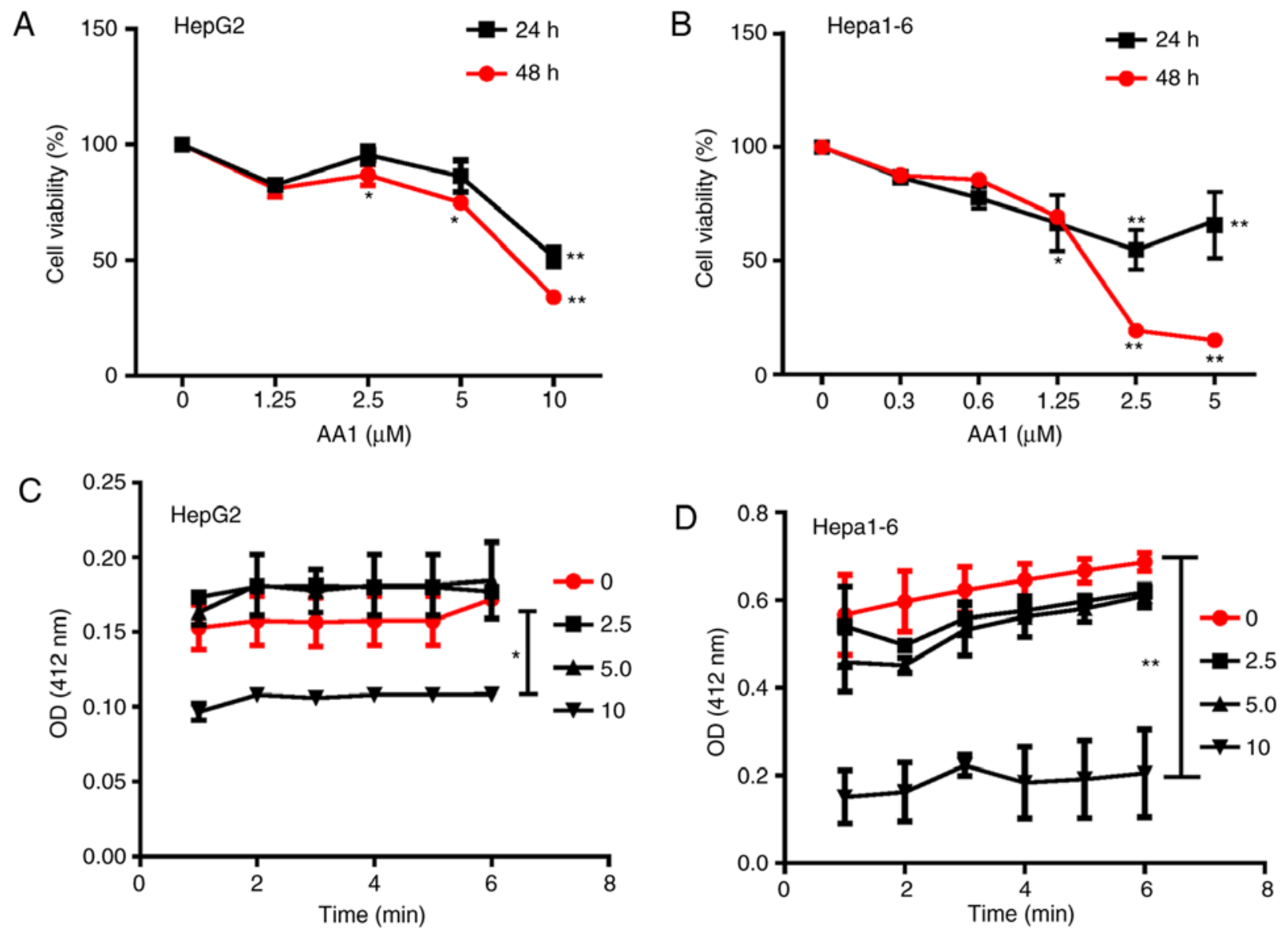

Figure 1. Targeting TrxR inhibits growth of liver cancer cells. (A) HepG2 and (B) Hepa1-6 cells were treated with designated concentrations of AA1 for 24 or $48 \mathrm{~h}$ and cell viability was determined using the MTT assay. Following treatment with AA1, the activity of TrxR in (C) HepG2 and (D) Hepa1-6 cells was tested using a 3-carboxy-4-nitrophenyl disulfide assay and measuring absorbance at $420 \mathrm{~nm}$. Data are expressed as the mean \pm standard deviation from at least three independent experiments. ${ }^{*} \mathrm{P}<0.05$ and ${ }^{* *} \mathrm{P}<0.01$. TrxR, thioredoxin reductase; AA1, chloro(triethylphosphine)gold(I); OD, optical density.

Reverse transcription-quantitative polymerase chain reaction analysis. Total RNA was extracted from cells using TRIzol (Invitrogen; Thermo Fisher Scientific, Inc.) and used to synthesize cDNA using M-MLV Reverse Transcriptase (Invitrogen; Thermo Fisher scientific, Inc.) in accordance with the manufacturer's protocol. The mRNA level of Bcl-2 was determined by Reverse transcription-quantitative PCR (RT-qPCR) with SYBR Green Master Mix (Roche Diagnostics, Indianapolis, IN, USA) using an iCycleriQ real-time PCR system (Bio-Rad Laboratories, Inc., Hercules, CA, USA). qPCR amplification was conducted for 35 cycles, each cycle consisting of denaturation $\left(95^{\circ} \mathrm{C}\right.$ for $\left.5 \mathrm{sec}\right)$, annealing $\left(55^{\circ} \mathrm{C}\right.$ for $\left.20 \mathrm{sec}\right)$ with a single fluorescence measurement taken at the end of the annealing step, and extension $\left(72^{\circ} \mathrm{C}\right.$ for $\left.20 \mathrm{sec}\right)$. The $\Delta \Delta \mathrm{Cq}$ method was applied for gene number determination (21). The expression of human Bcl-2 was normalized to GAPDH levels. Primer sequences for quantitative real-time PCR were as follows: GAPDH (forward primer, 5'-TGCACCACCAACTGCTTAGC-3'; reverse primer, 5'-GGCATGGACTGTGGTCATGAG-3') and Bcl-2 (forward primer, 5'-CTGAGTACCTGAACCGGCA-3'; reverse primer, 5'-GAGAAATCAAACAGAGGCCG-3').

Western blotting. Total protein was extracted from cells lysed with a RIPA lysis buffer (Beyotime Institute of Biotechnology) and the concentrations were determined with bicinchoninic acid methods. Then, proteins (30 $\mu \mathrm{g}$ /lane) were separated by SDS-PAGE on a $10 \%$ polyacrylamide gel and transferred onto polyvinylidene difluoride membranes membranes (EMD Millipore, Billerica, MA, USA). The membranes were blocked with TBS buffer containing 5\% non-fat milk for $1 \mathrm{~h}$ at room temperature. Then the protein were incubated with specific antibodies (1:1,000): Phosphorylated (p)-38 (cat. no. 4511; Cell Signaling Technology, Inc., Danvers, MA, USA), P38 (cat. no. 8690; Cell Signaling Technology, Inc.), p-mitogen-activated protein kinase 8 (p-JNK; cat. no. 4668S; Cell Signaling Technology, Inc.), JNK (cat. no. 3708S; Cell Signaling Technology, Inc.), p-extracellular signal regulated kinase (p-ERK; cat. no. 14227S; Cell Signaling Technology, Inc.), ERK (cat. no. 4348S; Cell Signaling Technology, Inc.), p-mammalian target of rapamycin (p-mTOR; cat. no. ab109268; Abcam, Cambridge, UK), mTOR (cat. no. ab32028; Abcam), p62 (cat. no. ab109012; Abcam), light chain-3 (LC3B; cat. no. 2275S), Bcl-2 (cat. no. ab32124; Abcam) and $\beta$-actin (cat. no. 3700; Cell Signaling Technology, Inc.). The membranes were then washed and incubated with goat anti-rabbit (cat. no. A0208; Beyotime Institute of Biotechnology) or goat anti-mouse (cat. no. A0216; Beyotime Institute of Biotechnology) horseradish peroxidase-conjugated secondary antibody $(1: 10,000)$ for $1 \mathrm{~h}$. After being washed, the membranes were developed using enhanced chemiluminescence (ECL; EMD Millipore). 
A
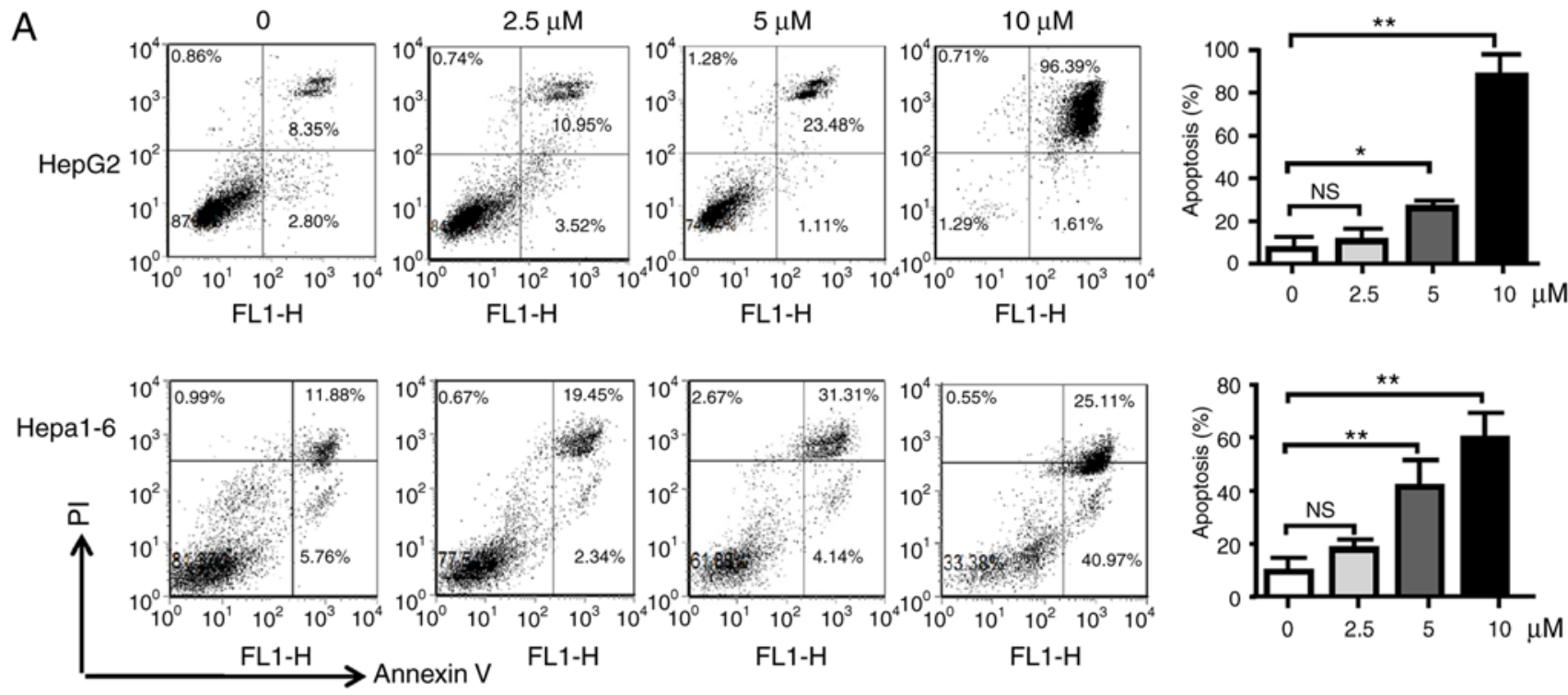

B

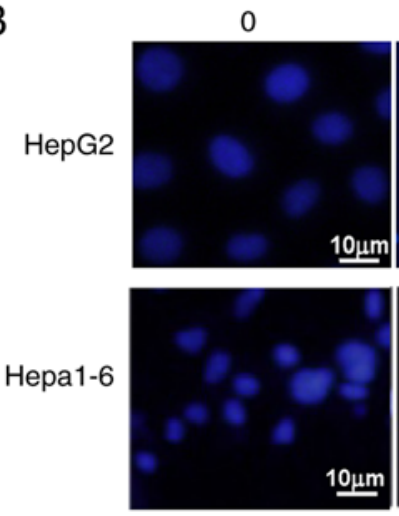

$5 \mu \mathrm{M}$

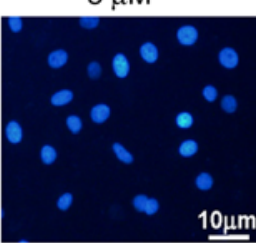

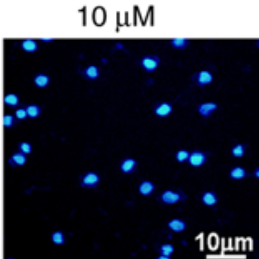

C
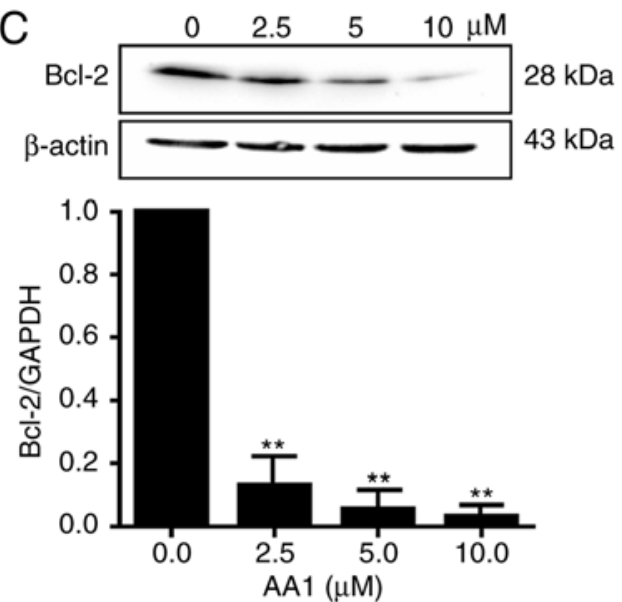

Figure 2. Inhibition of thioredoxin reductase induces apoptosis in liver cancer cells. HepG2 and Hepa1-6 cells were treated with AA1 for 12 h. (A) The percentage of cells undergoing apoptosis was determined by flow cytometry using an Annexin V/PI assay. (B) HepG2 and Hepa1-6 cells treated with AA1 for $12 \mathrm{~h}$ were stained with DAPI. Images were acquired by fluorescence microscopy (scale bar $10 \mu \mathrm{m}$ ). (C) Expression of the anti-apoptotic gene Bcl-2 was assayed by quantitative polymerase chain reaction and western blotting following treatment by AA1 for $12 \mathrm{~h}$. Data are expressed as the mean \pm standard deviation of at least three independent experiments. " $\mathrm{P}<0.05$ and ${ }^{* * *} \mathrm{P}<0.01$ vs. the untreated group $(0 \mu \mathrm{M})$. PI, propidium iodide; Bcl-2, B cell lymphoma-2; AA1, chloro(triethylphosphine)gold(I); NS, not significant.

Densitometric analysis of blots was performed in Image J (version 1.41o; National Institutes of Health, Bethesda, MD, USA).

Autophagy flux assays. HepG2 cells were seeded in a 12-well plate $\left(1.5 \times 10^{5}\right)$ and infected with Ad-mCherry-green fluorescence protein (GFP)-LC3B (Beyotime Institute of Biotechnology) (Multiplicity of infection 15 ) for $48 \mathrm{~h}$, then preincubated for $2 \mathrm{~h}$ with or without $1 \mathrm{mg} / \mathrm{ml} \mathrm{N}$-acetylcysteine (NAC). This was followed by treatment with $10 \mu \mathrm{M}$ AA1 for $6 \mathrm{~h}$. Cells were fixed with $4 \%$ paraformaldehyde for $24 \mathrm{~h}$ at $4^{\circ} \mathrm{C}$ and microphotographs of mCherry-GFP-LC3 fluorescence were acquired by fluorescence microscopy (Olympus Corporation).

Flow cytometry. Infiltrating mononuclear cells were isolated from the whole tumor tissue. Flow cytometric analysis was performed using BD FACSCalibur and FACSAria III instruments. Antibodies used in this study included FITC-labeled
anti-Natural killer (NK)1.1 (cat. no. 11-5941-85) and anti-cluster of differentiation (CD)4 (cat. no. 11-0041-82); phycoerythrin (PE)-labeled anti-mouse-CD69 (cat. no. 12-0691-83); PE-cyanine 5.5-labeled anti-mouse CD3e (cat. no. 45-0031-82) and PE-labeled anti-CD8 (cat. no. 12-0081-82). Antibodies were obtained from eBioscience; Thermo Fisher Scientific, Inc. (22). The cells were blocked with $10 \%$ normal rat serum (prepared in our lab) for $30 \mathrm{~min}$, and stained with a saturating amount of the antibodies for $1 \mathrm{~h}$ at $4^{\circ} \mathrm{C}$, then washed with PBS for three times. Cells were acquired on a FACSCalibur flow cytometer (BD Bioscience) and analyzed using WinMDI version 2.8 software (The Scripps Research Institute, San Diego, CA, USA).

Statistical analyses. All values are presented as the mean \pm standard error of the mean of three independent experiments. Statistical analysis was performed using a paired Student's t-test or one-way analysis of variance followed by Tukey's post-hoc test. $\mathrm{P}<0.05$ was considered to indicate a statistically significant difference. 
A
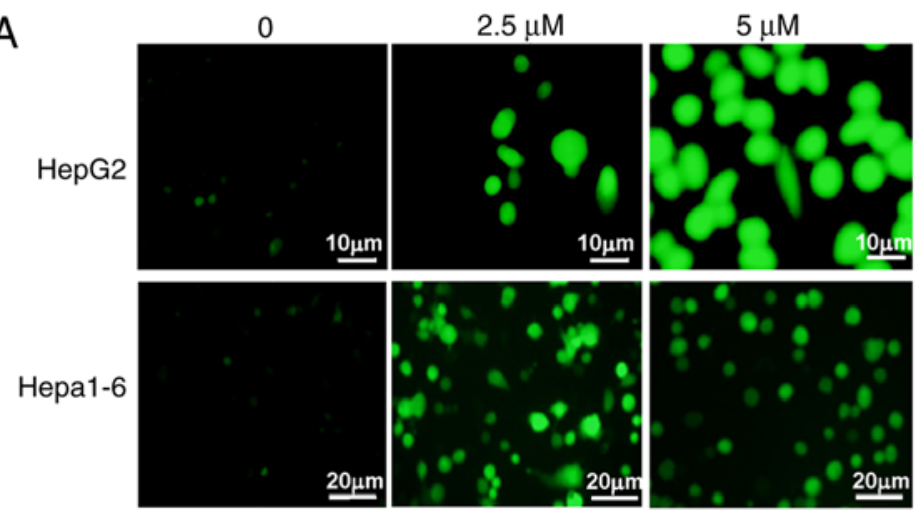

C
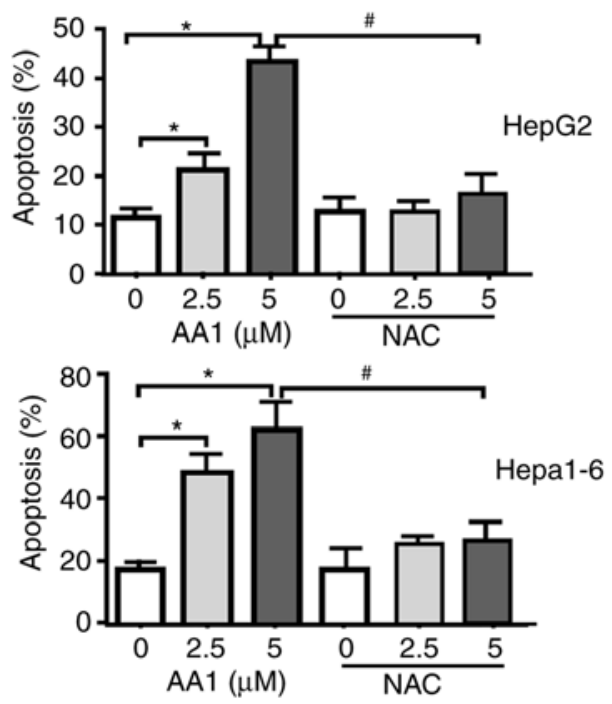

Hepa1-6

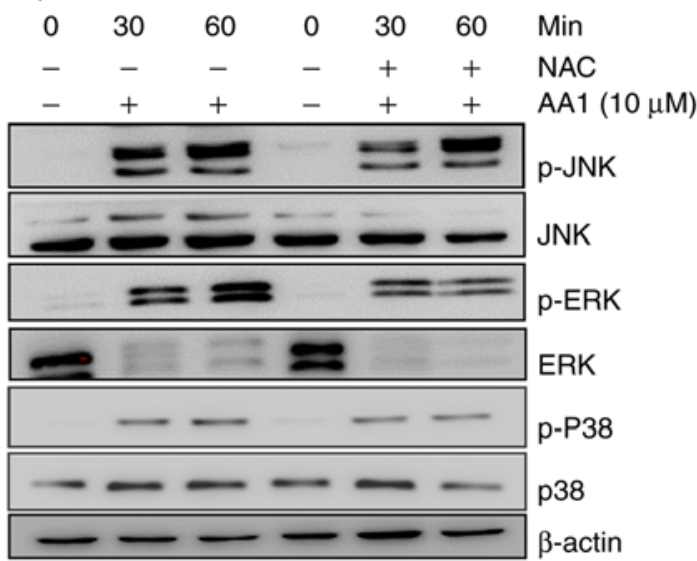

Figure 3. Inhibition of TrxR induces apoptosis in liver cancer in a ROS-dependent manner. HepG2 and Hepa1-6 cells were treated with different concentrations of AA1 for $6 \mathrm{~h}$. Accumulation of ROS in the cells was evaluated following DCFH-DA staining. Images were acquired by fluorescence microscopy (scale bar, $10 \mu \mathrm{m}$ for HepG2 cells and $20 \mu \mathrm{m}$ for Hepa1-6 cells) (A) HepG2 and Hepa1-6 cells were either treated with AA1, pretreated with NAC followed by AA1 treatment, or treated with NAC alone for the designated periods of time. (B) Levels of p-p38-MAPK, p-JNK and p-ERK levels were examined by western blotting. (C) HepG2 and Hepa1-6 cells either pre-treated with NAC or untreated were subsequently treated with AA1 for 12 h. The percentage of cells undergoing apoptosis was detected by flow cytometry using an Annexin V/propidium iodide assay. Data are expressed as the mean \pm standard deviation from at least three independent experiments. ${ }^{*} \mathrm{P}<0.05$ : AA1-treated group vs. the untreated group $(0 \mu \mathrm{M})$; ${ }^{\#} \mathrm{P}<0.05$ : AA1+NAC vs. AA1-treated group. p-ERK, phosphorylated-extracellular signal regulated kinase; JNK, mitogen-activated protein kinase 8; MAPK, mitogen-activated protein kinase; NAC, $\mathrm{N}$-acetylcysteine; AA1, chloro(triethylphosphine)gold(I).

\section{Results}

Targeting TrxR inhibits liver cancer cell growth. To evaluate the feasibility of targeting $\operatorname{Trx} R$ in liver cancer, TrxR activity was first examined using a DNTB assay. Among various cancer cell lines including MDA-MB231 (breast cancer), Hela (cervical cancer), B16 (melanoma cells), K562 and HL-60 (leukemia cell), A549 (lung cancer), HepG2, H7402, PLC and HepG2.2.15 cells (liver cancer), liver cancer cell lines, including HepG2 and H7402, were demonstrated to exhibit a high level of TrxR activity (data not shown). Subsequently, the effects of the TrxR inhibitor AA1 on the growth of HepG2 cells and the mouse hepatoma cell line Hepa1-6 in vitro was analyzed using an MTT assay. As demonstrated in Fig. 1A and B, treatment with AA1 for 24 or $48 \mathrm{~h}$ inhibited the proliferation of HepG2 and Hepa1-6 cells significantly at $\geq 2.5 \mu \mathrm{M}$ $(\mathrm{P}<0.05)$. In addition, it was observed that TrxR activity was inhibited in HepG2 and Hepa1-6 cells treated with a range of AA1 concentrations and significant inhibition occurred at $10 \mu \mathrm{M}(\mathrm{P}<0.05$; Fig. $1 \mathrm{C}$ and $\mathrm{D})$. These results demonstrated that targeting TrxR can inhibit the growth of liver cancer cells in vitro.

Targeting TrxR induces apoptosis in liver cancer cells in a ROS-dependent manner. Cell cycle analysis demonstrated that TrxR inhibition by AA1 has no effect on the cell cycle progression of liver cancer cells (data not shown). Therefore, the pro-apoptotic effects of AA1 in liver cancer cell lines were examined using an Annexin V/PI staining assay. As demonstrated in Fig. 2A, HepG2 and Hepa1-6 cells underwent dose-dependent apoptotic cell death following treatment with AA1 for $12 \mathrm{~h}$, with a significant increase in apoptosis was demonstrated at $\geq 5 \mu \mathrm{M}(\mathrm{P}<0.05)$. Cell nuclear morphology was also examined as an indicator of apoptosis. As demonstrated in Fig. 2B, compared with the untreated cells, which remained dim, HepG2 cells treated with the TrxR inhibitor exhibited a 


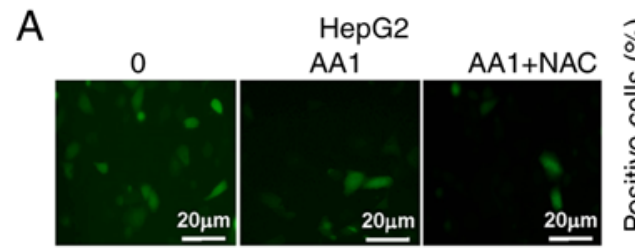

B

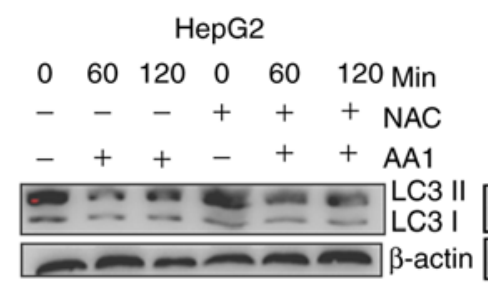

C

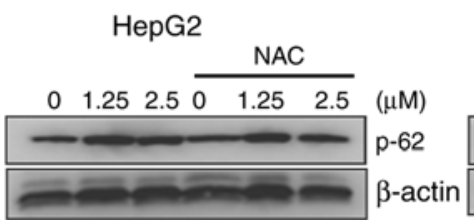

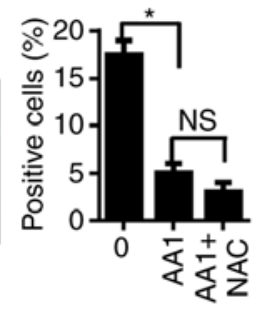

Hepa1-6

$\begin{array}{lllllll}0 & 60 & 120 & 0 & 60 & 120 & \text { Min }\end{array}$

$-\quad-\quad+++$ NAC

$-++-++\mathrm{AA} 1$
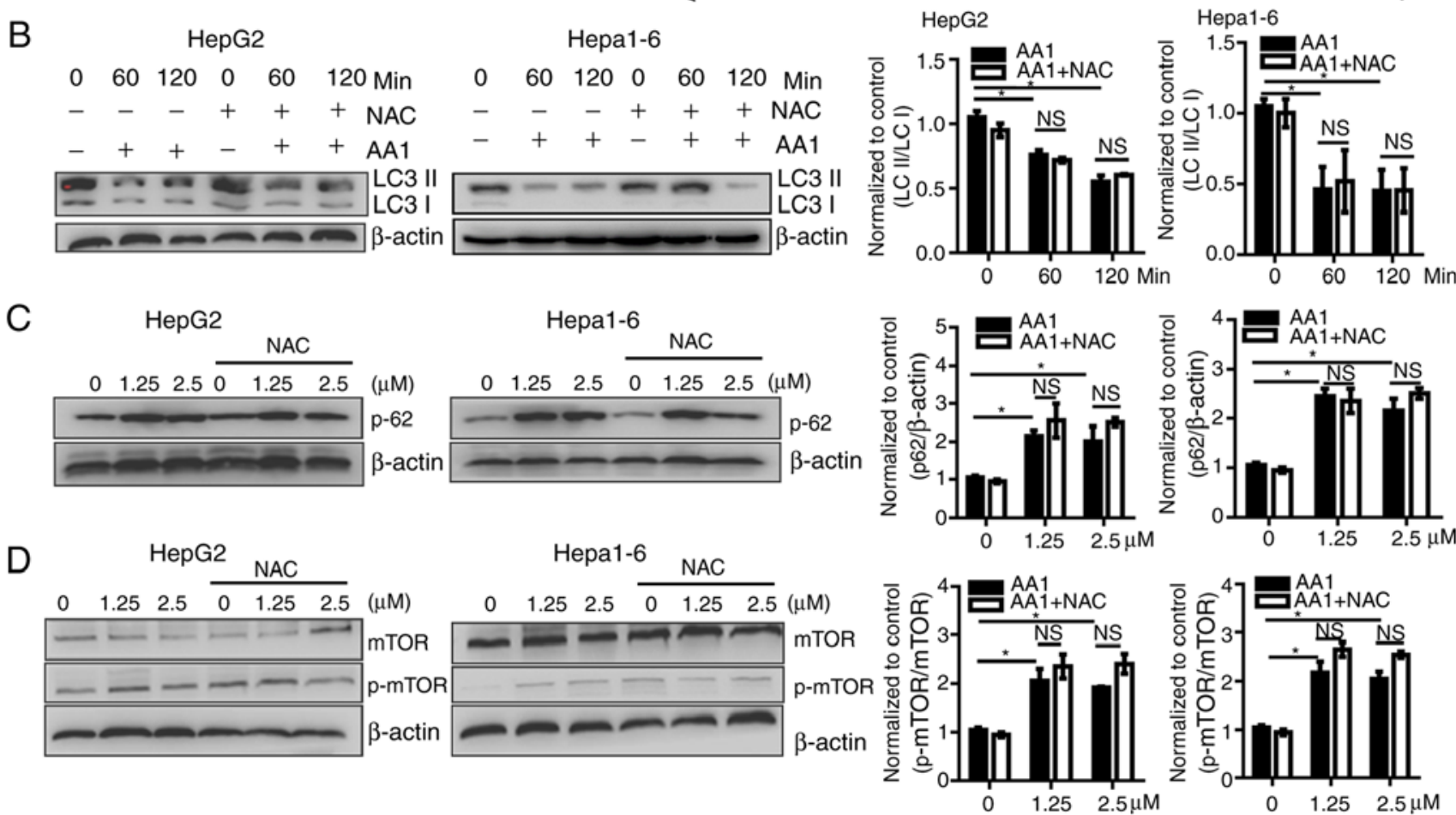

Figure 4. Targeting TrxR inhibits autophagy of liver cancer cells in a reactive oxygen species-independent manner. HepG2 or Hepa1-6 cells were infected with Ad-mCherry-green fluorescent protein-LC3B for $48 \mathrm{~h}$ and following pretreatment with NAC for $2 \mathrm{~h}$ or no treatment, cells were then treated with $10 \mu \mathrm{M}$ AA1 for $6 \mathrm{~h}$. (Aa) Autophagosomes were imaged by fluorescence microscopy (scale bar $20 \mu \mathrm{m}$ ), quantitative analysis of LC3 expression was presented in (Ab), (B) LC3-II and LC3-I levels were examined by western blotting following treatment with AA1 (10 $\mu \mathrm{M})$, AA1+NAC pretreated, or NAC alone for different time points in Hepa1-6 and HepG2 cells. (C) The levels of p62 protein were detected following treatment with an increasing concentration ( 0 - $2.5 \mu \mathrm{M})$ of AA1 for $3 \mathrm{~h}$ in Hepa1-6 and HepG2 cells with or without NAC pretreatment. (D) Activation of mTOR in HepG2 and Hepa1-6 cells treated as described above was detected by western blotting. The western blots are presented on the left and quantitative analysis is presented in the right panel. Experiments were run in triplicate. ${ }^{*} \mathrm{P}<0.05$ vs. the untreated group $(0 \mu \mathrm{M})$. mTOR, mammalian target of rapamycin; LC 3 , light chain 3; NAC, N-acetylcysteine; AA1, chloro(triethylphosphine) gold(I); TrxR, thioredoxin reductase; NS, not significant.

bright blue appearance and the nucleus appears to be condensed and fragmented. Examination of expression of the anti-apoptotic gene Bcl-2 by qPCR and western blotting demonstrated that inhibition of $\operatorname{Trx} \mathrm{R}$ significantly decreased expression in a dose-dependent manner in HepG2 cells ( $\mathrm{P}<0.01$; Fig. $2 \mathrm{C}$ ), a similar trend of Bcl-2 mRNA inhibition was also observed in Hep1-6 cells after AA1 treatment (data not shown).

It was reported that $\operatorname{TrxR}$ inhibition promotes apoptosis in a ROS-dependent manner in pancreatic and lung cancer cells $(9,23)$. Therefore, whether TrxR inhibition-induced apoptosis of liver cancer cells was associated with an increase in ROS levels was examined. Using the redox-sensitive fluorescent probe DCFH-DA, TrxR inhibition by AA1 was demonstrated to cause a dose-dependent increase in ROS levels in HepG2 and Hepa1-6 cells (Fig. 3A). The p38-mitogen associated protein kinase (MAPK) signaling pathway is activated by ROS production, which has previously been suggested to promote cell apoptosis (24). As demonstrated in Fig. 3B, TrxR inhibition by AA1 increases the levels of p-p38, p-JNK and p-ERK in a time-dependent manner; notably, the ROS inhibitor NAC almost completely abolished p38, JNK, ERK activation induced by AA1 in HepG2 and Hepa1-6 cells. Furthermore, AA1-induced pro-apoptotic effects in HepG2 and Hepa1-6 cells are almost abolished by pre-treatment with NAC (Fig. 3C). These results indicated that AA1-induced ROS activate the MAPK signal pathway and promote apoptosis in liver cancer cells.

Targeting TrxR inhibits autophagy of liver cancer cells in a ROS-independent way. As previously described, ROS induce autophagy which then contributes to a reduction of ROS levels. Autophagy serves important roles in cell survival as well as in the regulation of cell death, especially in apoptosis-signaling pathways. To investigate whether the activation of autophagy contributes to the effects of AA1, the activation of autophagy in AA1-treated HepG2 and Hepa1-6 cells was examined. LC3 expression was demonstrated to decease significantly in cells treated with AA1 for $6 \mathrm{~h}(\mathrm{P}<0.05)$; however, NAC treatment does not reverse autophagosome inhibition resulting from 
A

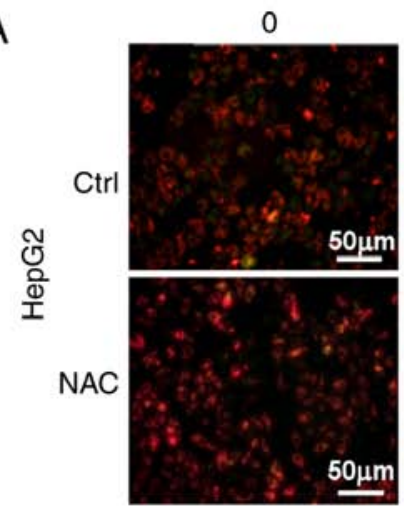

B

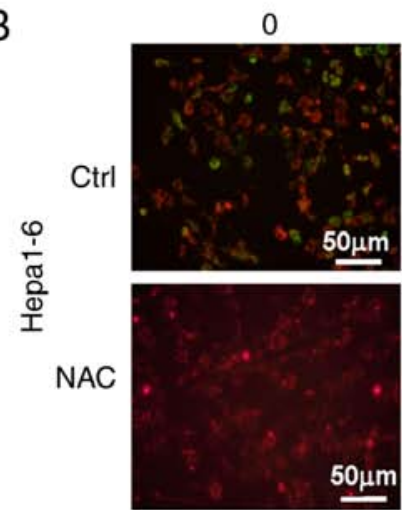

$2.5 \mu \mathrm{M}$

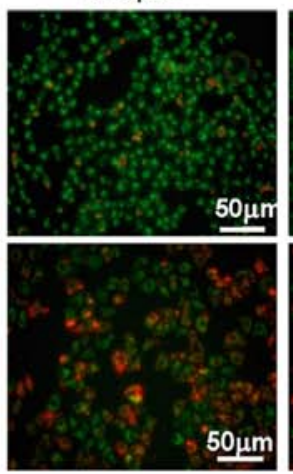

$1.25 \mu \mathrm{M}$

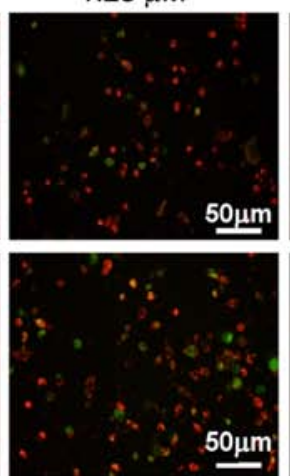

$5 \mu \mathrm{M}$

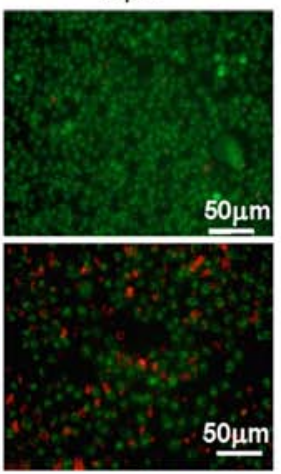

$2.5 \mu \mathrm{M}$

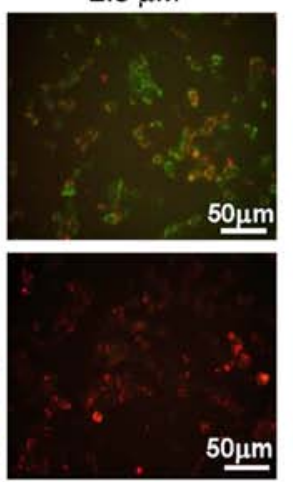

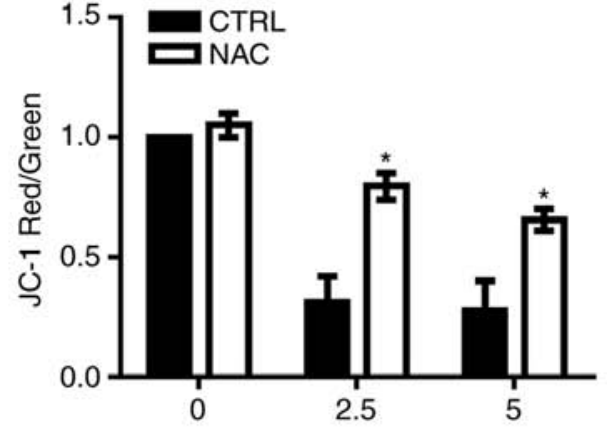

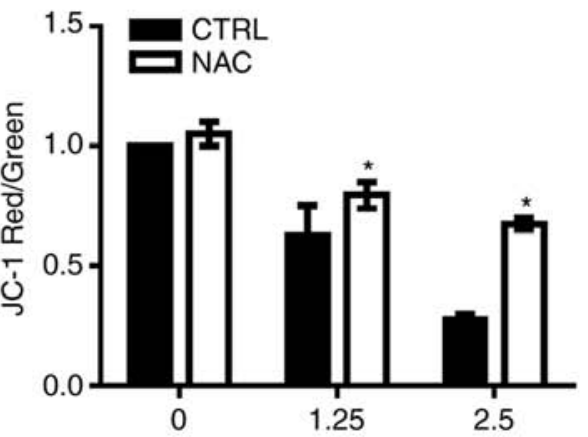

Figure 5. Targeting TrxR induces lesions in the mitochondrial membranes of liver cancer cells. (A) HepG2 cells and (B) Hepa1-6 cells were treated with different concentration of chloro(triethylphosphine)gold(I) for $6 \mathrm{~h}$ then incubated with the JC-1 probe (5 $\mu \mathrm{M})$ for 30 min. MMP was detected by fluorescence microscopy. Membrane depolarization is reflected in a shift from green to red. Images demonstrate one representative result from the assay, which was run in triplicate (scale bar $50 \mu \mathrm{m}$ ). Quantitative analysis of the MMP among groups. The ratio of red to green fluorescence was used as the indicator for MMP. Data are expressed as the mean \pm standard deviation from at least three independent experiments. ${ }^{*} \mathrm{P}<0.05$ : AA1-treated group vs. untreated group $(0 \mu \mathrm{M})$. MMP, mitochondrial membrane potential; TrxR, thioredoxin reductase; NAC, N-acetylcysteine; CTRL, control.

AA1 treatment (Fig. 4A). The conversion of LC3-I to LC3-II was monitored using western blot analysis. Consistently, the ratio of LC3-II to LC3-I in HepG2 and Hepa1-6 cells treated with AA1 decreased significantly compared with the control group $(\mathrm{P}<0.05)$. This effect is also observed following NAC pretreatment $(\mathrm{P}<0.05$; Fig. 4B).

The p62 protein has previously been demonstrated to be preferentially degraded by autophagy, so levels of p62 reflect alterations in autophagy (25). As the levels of p62 were examined by western blotting, it was noticed that the levels of p62 increased noticeably in 1.25 or $5 \mu \mathrm{M}$ AA1-treated HepG2 and Hepa1-6 cells, and that NAC does not influence the expression of p62 (Fig. 4C). These data further support that AA1 inhibition of autophagy is not dependent on ROS.

Activity of the mTOR is associated with the status of autophagy (26). TrxR inhibition with increasing concentrations of AA1 was demonstrated to significantly induce phosphorylation of mTOR in Hepa1-6 and HepG2 cells $(\mathrm{P}<0.05)$ and NAC pretreatment does not prevent AA1-induced mTOR activation (Fig. 4D). Together, these results indicate that targeting TrxR inhibits autophagy in liver cancer cells in an ROS-independent manner.

Inhibition of TrxR induces mitochondrial membrane lesions in liver cancer cells. Since increases in ROS may occur due to dysfunctional mitochondria (9), the MMP was analyzed in HepG2 and Hepa1-6 cells treated with AA1 using JC-1 dye. An increase in green fluorescence and a decrease of red fluorescence was noted, indicating a decline in the MMP in AA1-treated cells without NAC. NAC significantly suppressed the inhibition of MMP induced by AA1 in HepG2 $(\mathrm{P}<0.05$; Fig. 5A) and Hepa1-6 cells at $2.5 \mu \mathrm{M}(\mathrm{P}<0.05$; Fig. 5B). These observations provide a clear indication that TrxR inhibition induces lesions in the mitochondrial membrane in liver cancer cells.

Targeting TrxR inhibits tumor growth in HepG2 tumor-bearing nude mice. To investigate the effects of targeting Trx $R$ on liver cancer growth in vivo, AA1 was administered to nude mice subcutaneously injected with $2 \times 10^{6} \mathrm{HepG} 2$ cells. A widely used anticancer drug cis-diamine dichloroplatinum (Cis-Dic) was used for comparison (Fig. 6A). The body weights of AA1-and Cis-Dic-treated groups were not significantly different from the untreated control group (Fig. 6B). The size of the tumors in the AA1- and Cis-Dic-treated mice were significantly smaller compared with the control mice, with the inhibitory effects of AA1 similar to Cis-Dic ( $\mathrm{P}<0.01$; Fig. 6C and 6D). Furthermore, as demonstrated in Fig. 6E, AA1 treatment significantly increases the expression of ROS in HepG 2 cells isolated from tumor-bearing nude mice $(\mathrm{P}<0.01)$. These data suggest that TrxR inhibition efficiently inhibits the growth of liver cancer in vivo. 
A
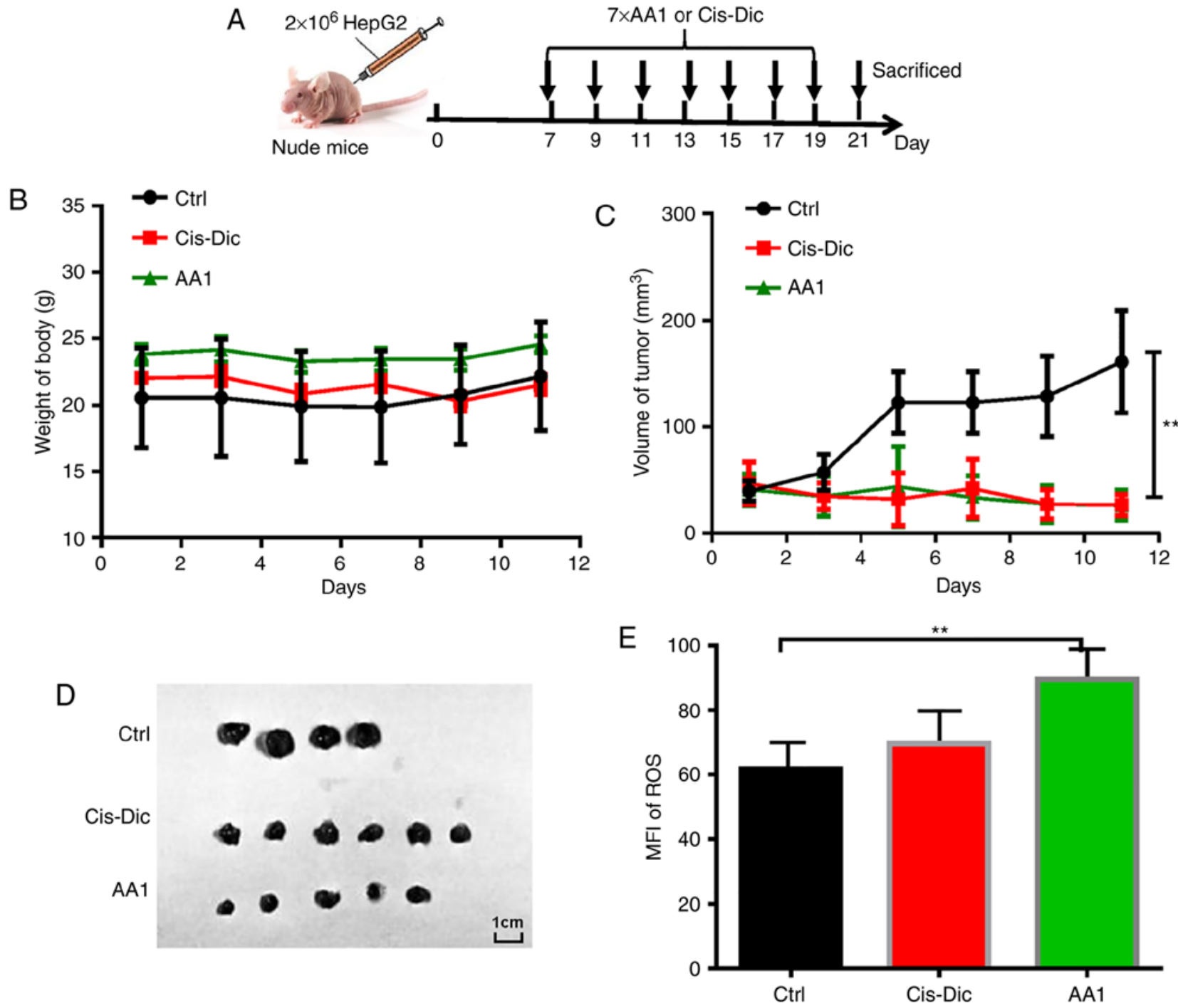

Figure 6. AA1 inhibits tumor growth in vivo. Nude mice were inoculated with $2 \times 10^{6} \mathrm{HepG} 2$ cells. (A) Beginning at seven days post-inoculation, mice were intraperitoneally injected with AA1 $(25 \mathrm{mg} / \mathrm{kg}$ ) or Cis-Dic $(3 \mathrm{mg} / \mathrm{kg})$ every two days for a total of seven injections. Solvent was used as a control. (B) The side effects of treatments were evaluated in terms of body weight variation. (C) Tumor growth curves were generated for the experimental period. Data are presented as the mean \pm standard deviation. (D) Tumors from the treated or control groups. (E) The ROS levels in tumor cells isolated from mice treated as above. Data presented represents the mean \pm standard deviation of $n=6$ and were analyzed with an analysis of variance test. ${ }^{* *} \mathrm{P}<0.01 \mathrm{vs}$. ctrl (PBS injection). ROS reactive oxygen species; Cis-Dic, cisplatin; AA1, chloro(triethylphosphine)gold(I); MFI, mean fluorescence index.

Targeting TrxR improves the tumor microenvironment. To identify whether TrxR inhibition affects the tumor microenvironment, another mouse model was adopted with an intact immune system. A total of $2 \times 10^{6}$ Hepa1- 6 cells were inoculated into $\mathrm{C} 57 \mathrm{BL} / 6$ mice and beginning seven days post-inoculation, AA1 or a solvent control were administered every two days for a total of seven injections (Fig. 7A). Similar to what was observed in HepG2 tumor-bearing nude mice, the growth of liver cancer was significantly suppressed by AA1 treatment as compared with the control group $(\mathrm{P}<0.01$; Fig. $7 \mathrm{~B}$ and $7 \mathrm{C})$ and is accompanied by a significant increase in ROS levels $(\mathrm{P}<0.01$; Fig. 7D). Next mononuclear cells were isolated from tumor tissues and the phenotypes of immune cells were analyzed. Compared with the control mice, a significantly increased infiltration of mononuclear cells was observed in tumor tissues from mice treated with AA1 $(\mathrm{P}<0.05$; Fig. 7E). Since it is well known that $\mathrm{CD}^{+} \mathrm{T}$ and natural killer $(\mathrm{NK})$ cells serve key roles in antitumor immunity, the frequency and activation of these cells was next evaluated by fluorescence-activated cell sorting. As demonstrated in Fig. 7F, although the percentage of $\mathrm{CD}^{+} \mathrm{T}$ cells is not significantly affected by AA1 treatment, the expression of the activation marker CD69 is significantly increased in $\mathrm{CD}^{+} \mathrm{T}$ cells from AA1-treated mice $(\mathrm{P}<0.05)$. In addition, the frequency and CD69 expression levels of NK cells increased in tumor tissues from AA1-treated mice, while the CD69 upregulation was non-significant. (Fig. 7G). These data suggested that targeting TrxR can stimulate the activation of the immune response, enhancing antitumor efficiency.

\section{Discussion}

In the present study, it was demonstrated that targeting TrxR inhibits the growth of liver cancer cells by inducing apoptosis through a ROS-dependent pathway. Mechanistically, TrxR inhibition results in the production of ROS, which activates the MAPK signaling pathway. Additionally, lesions in the 
A
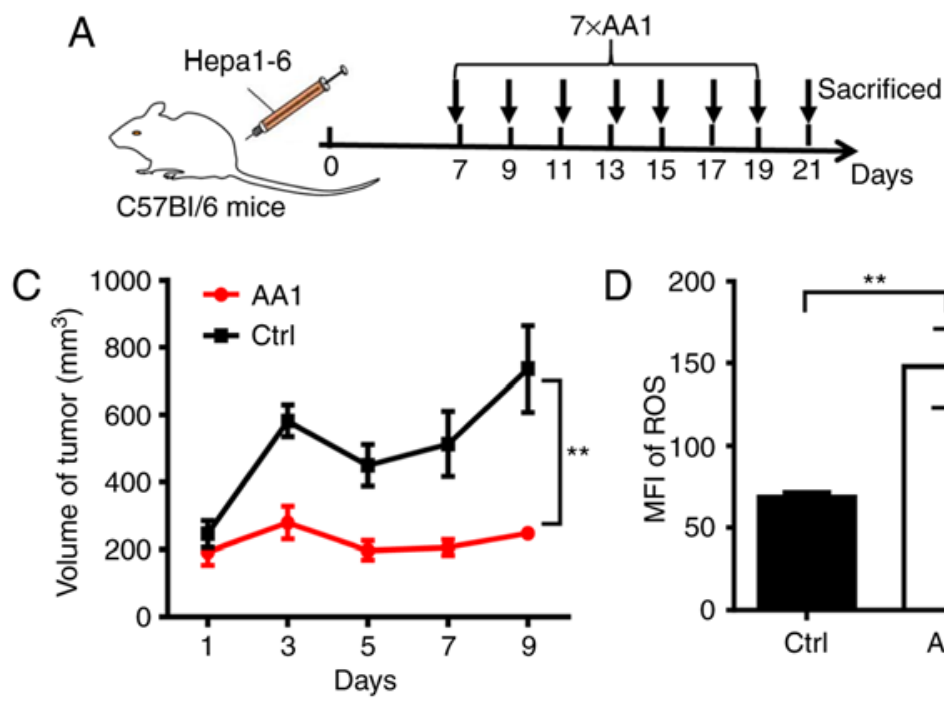

B

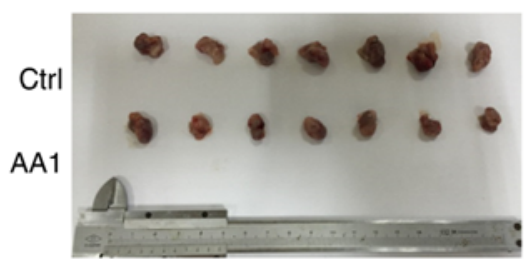

$\mathrm{E}$

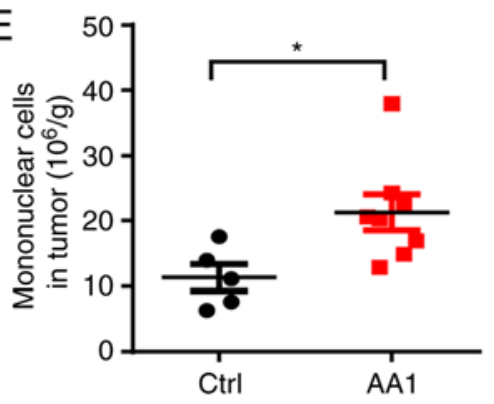

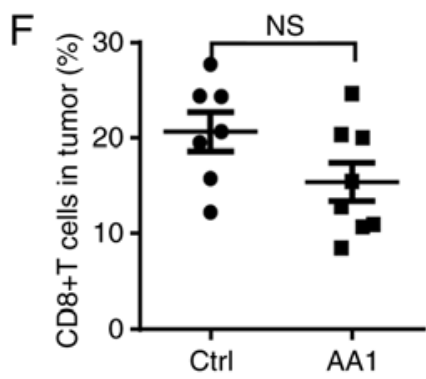
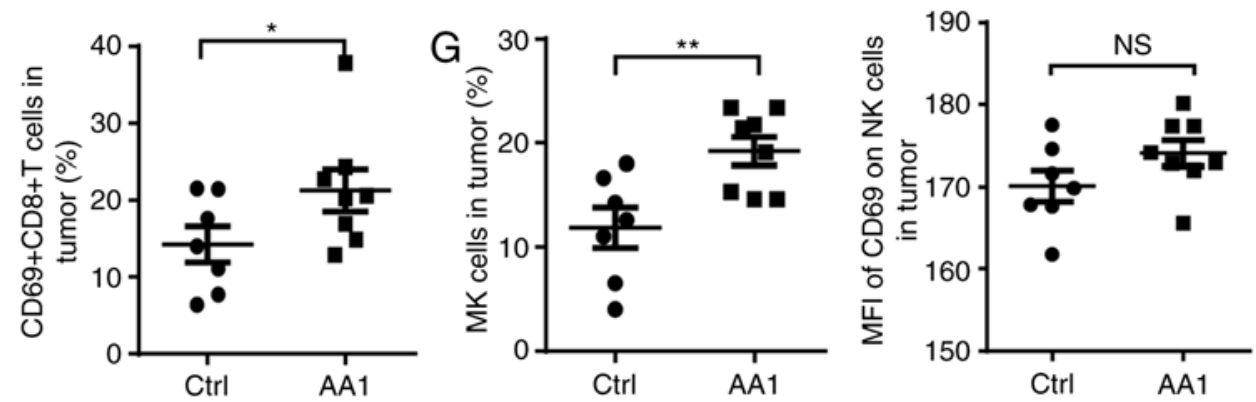

Figure 7. Targeting TrxR improves the tumor microenvironment. C57BL/6 mice were inoculated with $2 \times 10^{6} \mathrm{Hepa} 1-6$ cells. (A) At seven days post-inoculation, mice were injected intraperitoneally with AA1 $(25 \mathrm{mg} / \mathrm{kg}$ ) or solvent (Ctrl) every two days for a total of seven injections. (B) Gross pathology was observed and (C) tumor growth curves were generated following treatment with AA1. (D) ROS levels in tumor cells from C57BL/6 mice treated as above. (E) Infiltrating mononuclear cells from tumor tissues of Hepa1-6 tumor-bearing mice were isolated and analyzed by flow cytometry and a cell count performed. The frequency and activation of infiltrated (F) $\mathrm{CD}^{+} \mathrm{T}$ cells and $(\mathrm{G}) \mathrm{NK}$ cells in tumor tissue were analyzed. Data demonstrated represent the mean \pm standard deviation $\mathrm{n}=7$ and were analyzed with analysis of variance. ${ }^{*} \mathrm{P}<0.05$ and $^{* *} \mathrm{P}<0.01$ : vs. ctrl (PBS injection). ROS, reactive oxygen species; Ctrl, control; NK, natural killer; AA1, chloro(triethylphosphine)gold(I); NS, not significant; CD, cluster of differentiation.

mitochondrial membranes in liver cancer are induced by targeting TrxR and are accompanied by the inhibition of the protein kinase B (Akt)/mTOR pathway and autophagy. The results of xenograft experiments in nude mice were highly consistent with in vitro studies. Notably, TrxR inhibition improves the tumor immune microenvironment in mouse model.

The Trx/TrxR system is a major protein disulfide reduction system in mammalian cells. TrxR is required to convert oxidized Trx into its functional reductive form, which can scavenge ROS and improves cell viability under oxidative stress (27). TrxR, is overexpressed in a number of tumor cells including liver cancer, pancreatic cancer and lung cancer, and has emerged as a novel target for cancer treatment $(9,23)$. To date, a number of synthetic and natural therapeutic compounds that exhibit anticancer properties have been classified as TrxR inhibitors. The results of the present study demonstrated that TrxR inhibition inhibits the growth of liver cancer in vitro and in vivo. Although no disruption to the cell cycle of HepG2 cells is observed following treatment with the TrxR inhibitor AA1, the number of apoptotic cells was increased. Further investigation demonstrated that the levels of ROS increased with TrxR inhibition and mediated AA1-induced liver cancer cell apoptosis, in conjunction with downregulation of $\mathrm{Bcl}-2$. This is consistent with previous observations demonstrating that the accumulation of ROS can result in DNA damage and apoptosis $(24,28)$. Trx is a physiological inhibitor of mitogen-activated protein kinase kinase kinase 5 (ASK1) that interacts directly and therefore disrupts ASK1-p38-MAPK-dependent apoptosis (9,29,30). Given that this interaction only occurs with Trx in its reduced form, AA1 likely reduces the binding of ASK1 to Trx. As a result, free ASK1 leads to phosphorylation of p38-MAPK, which is detected in liver cancer cells, as well as the activation of JNK and ERK.

The phosphoinositol 3 kinase/Akt/mTOR signaling pathway and the Ras/Raf1/ERK1/2 pathway are known to regulate autophagy in cellular responses $(31,32)$. In the present study, the activation of mTOR signaling was demonstrated and the conversion of LC3-I to LC3-II was decreased by AA1 treatment, which is consistent with observations of other types of cancer treated with TrxR inhibitors $(33,34)$. Targeting TrxR induces the inhibition of autophagy independently of ROS. This may mean that AA1 directly inhibits autophagy, or autophagy inhibition occurs prior to ROS accumulation. These results demonstrate the impact of the redox environment on autophagy-apoptosis interplay in various cancer cells.

Mitochondria serve an important role in the regulation of apoptosis and the mitochondria-mediated apoptosis pathway is accompanied by MMP depolarization, followed by pro-apoptotic 
molecule release from the mitochondria into the cytosol (35). In the present study, JC-1 was used as a fluorescent probe, which selectively enters into mitochondria and undergoes a reversible color alteration from green to red as the membrane potential increases. TrxR inhibition was observed to decrease MMP in liver cancer cells treated with AA1, demonstrating an additional mechanism contributing to TrxR inhibition-induced apoptosis in liver cancer cells.

A previous study demonstrated that $\mathrm{CD} 4^{+} \mathrm{CD} 25^{+} \mathrm{Foxp} 3^{+}$ regulatory $\mathrm{T}$ cells (Tregs) are enriched in the tumor microenvironments of melanoma patient and demonstrate a positive correlation with $\mathrm{Trx}$ levels, while $\mathrm{CD}^{+} \mathrm{T}$ cell responses were not evaluated (36). In the present study, mononuclear cells were observed to accumulate in the tumor tissue following AA1 treatment of C57BL/6 Hepa1-6 tumor-bearing mice and infiltrating $\mathrm{CD}^{+} \mathrm{T}$, and $\mathrm{NK}$ cells are activated. The present study hypothesized that AA1 treatment may inhibit the function of Tregs, then the inhibition of $\mathrm{CD}^{+} \mathrm{T}$ cells and NK cells was reversed in tumor environment. Importantly, in the present study and another previous study hepatocellular damage following TrxR inhibition was not observed (16). Although AA1 demonstrates interesting anticancer effects in liver cancer, more work needs to be done to better understand the underlying immunological mechanisms.

In conclusion, the results of the present study indicate that a disruption in the redox balance generated by targeting TrxR can efficiently inhibit the growth of liver cancer in vitro and in vivo. TrxR inhibition induces apoptotic cell death through ROS and mitochondrial dysfunction. In addition, blockage of autophagy increases the sensitivity of liver cancer to TrxR inhibition. Notably, TrxR inhibition results in a potent immune response in a mouse model. Together, the results of the present study indicate that TrxR is a potential antitumor target for liver cancer chemotherapy.

\section{Acknowledgements}

The authors would like to thank Professor Minyong Li (School of Pharmaceutical Sciences, Shandong University) for providing the potent TrxR inhibitor, AA1.

\section{Funding}

The present study was supported by the Shandong Provincial Key Research and Development Program (grant no. 2017GSF18159), and the Shandong Provincial Natural Science Foundation (grant no. ZR2017BH029), the Natural Science Foundation of China (grant no. 81373222) and the Fundamental Research Fund of Shandong University (grant no. 2017JC004).

\section{Availability of data and materials}

The analyzed datasets generated during the study are available from the corresponding author on reasonable request.

\section{Authors' contributions}

QH and JZ designed the study. HL and GW performed the experiments. HL and QH analyzed the data. QH wrote the manuscript.
All authors have read and approved the final version of the manuscript.

\section{Ethics approval and consent to participate}

The animal experiments were approved by the Research Ethics Committee of Shandong University.

\section{Patient consent for publication}

Not applicable.

\section{Competing interests}

The authors declare that they have no competing interests.

\section{References}

1. Nault JC, Sutter O, Nahon P, Ganne-Carrié N and Séror O: Percutaneous treatment of hepatocellular carcinoma: State of the art and innovations. J Hepatol: Oct 13, 2017 (Epub ahead of print).

2. Kim E, Kim D, Lee JS, Yoe J, Park J, Kim CJ, Jeong D, Kim S and Lee Y: Capicua suppresses hepatocellular carcinoma progression by controlling ETV4-MMP1 axis. Hepatology 67: 2287-2301, 2018.

3. Shen Q, Eun JW, Lee K, Kim HS, Yang HD, Kim SY, Lee EK, Kim T, Kang K, Kim S, et al: BANF1, PLOD3, SF3B4 as early-stage cancer decision markers and drivers of hepatocellular carcinoma. Hepatology 67: 1360-1377, 2018.

4. Finn RS, Zhu AX, Farah W, Almasri J, Zaiem F, Prokop LJ, Murad MH and Mohammed K: Therapies for advanced stage hepatocellular carcinoma with macrovascular invasion or metastatic disease: A systematic review and meta-analysis. Hepatology 67: 422-435, 2018.

5. Dietrich P, Koch A, Fritz V, Hartmann A, Bosserhoff AK and Hellerbrand C: Wild type Kirsten rat sarcoma is a novel microRNA-622-regulated therapeutic target for hepatocellular carcinoma and contributes to sorafenib resistance. Gut 67: 1328-1341, 2018.

6. Ray EM and Sanoff HK: Optimal therapy for patients with hepatocellular carcinoma and resistance or intolerance to sorafenib: Challenges and solutions. J Hepatocell Carcinoma 4: 131-138, 2017.

7. Saccoccia F, Angelucci F, Boumis G, Carotti D, Desiato G, Miele AE and Bellelli A: Thioredoxin reductase and its inhibitors. Curr Protein Pept Sci 15: 621-646, 2014.

8. Zhang J, Li X, Han X, Liu R and Fang J: Targeting the thioredoxin system for cancer therapy. Trends Pharmacol Sci 38: 794-808, 2017.

9. Cheng X, Holenya P, Can S, Alborzinia H, Rubbiani R, Ott I and Wölfl S: A TrxR inhibiting gold(I) NHC complex induces apoptosis through ASK1-p38-MAPK signaling in pancreatic cancer cells. Mol Cancer 13: 221, 2014.

10. Hellfritsch J, Kirsch J, Schneider M, Fluege T, Wortmann M, Frijhoff J, Dagnell M, Fey T, Esposito I, Kölle P, et al: Knockout of mitochondrial thioredoxin reductase stabilizes prolyl hydroxylase 2 and inhibits tumor growth and tumor-derived angiogenesis. Antioxid Redox Signal 22: 938-950, 2015.

11. Harris IS, Treloar AE, Inoue S, Sasaki M, Gorrini C, Lee KC, Yung KY, Brenner D, Knobbe-Thomsen CB, Cox MA, et al: Glutathione and thioredoxin antioxidant pathways synergize to drive cancer initiation and progression. Cancer Cell 27: 211-222, 2015.

12. Benhar M, Shytaj IL, Stamler JS and Savarino A: Dual targeting of the thioredoxin and glutathione systems in cancer and HIV. J Clin Invest 126: 1630-1639, 2016.

13. Zhang D, Xu Z, Yuan J, Zhao YX, Qiao ZY, Gao YJ, Yu GA, Li J and Wang H: Synthesis and molecular recognition studies on small-molecule inhibitors for thioredoxin reductase. J Med Chem 57: 8132-8139, 2014.

14. Rubbiani R, Kitanovic I, Alborzinia H, Can S, Kitanovic A, Onambele LA, Stefanopoulou M, Geldmacher Y, Sheldrick WS, Wolber G, et al: Benzimidazol-2-ylidene gold(I) complexes are thioredoxin reductase inhibitors with multiple antitumor properties. J Med Chem 53: 8608-8618, 2010. 
15. Li C, Peng Y, Mao B and Qian K: Thioredoxin reductase: A novel, independent prognostic marker in patients with hepatocellular carcinoma. Oncotarget 6: 17792-17804, 2015.

16. Zheng X, Ma W, Sun R, Yin H, Lin F, Liu Y, Xu W and Zeng H: Butaselen prevents hepatocarcinogenesis and progression through inhibiting thioredoxin reductase activity. Redox Biol 14: 237-249, 2018

17. López-Terrada D, Cheung SW, Finegold MJ and Knowles BB: Hep G2 is a hepatoblastoma-derived cell line. Hum Pathol 40: $1512-1515,2009$

18. Sutton BM, McGusty E, Walz DT and DiMartino MJ: Oral gold. Antiarthritic properties of alkylphosphinegold coordination complexes. J Med Chem 15: 1095-1098, 1972.

19. Yang Y,Zheng B, Han Q, Zhang C, Tian Z and Zhang J: Targeting blockage of STAT3 inhibits hepatitis B virus-related hepatocellular carcinoma. Cancer Biol Ther 17: 449-456, 2016.

20. Chen W, Zou P, Zhao Z, Weng Q, Chen X, Ying S, Ye Q, Wang Z, Ji J and Liang G: Selective killing of gastric cancer cells by a small molecule via targeting TrxR1 and ROS-mediated ER stress activation. Oncotarget 7: 16593-16609, 2016

21. Livak KJ and Schmittgen TD: Analysis of relative gene expression data using real-time quantitative PCR and the 2(-Delta Delta C(T)) method. Methods 25: 402-408, 2001.

22. Yang Y, Han Q, Hou Z, Zhang C, Tian Z and Zhang J: Exosomes mediate hepatitis B virus (HBV) transmission and NK-cell dysfunction. Cell Mol Immunol 14: 465-475, 2017.

23. Arambula JF, McCall R, Sidoran KJ, Magda D, Mitchell NA, Bielawski CW,Lynch VM, Sessler JL and Arumugam K: Targeting antioxidant pathways with ferrocenylated $N$-heterocyclic carbene supported gold(I) complexes in A549 lung cancer cells. Chem Sci 7: 1245-1256, 2016

24. Gan P, Gao Z, Zhao X and Qi G: Surfactin inducing mitochondria-dependent ROS to activate MAPKs, NF- $\kappa \mathrm{B}$ and inflammasomes in macrophages for adjuvant activity. Sci Rep 6 : 39303,2016

25. Kim J, Kundu M, Viollet B and Guan KL: AMPK and mTOR regulate autophagy through direct phosphorylation of Ulk1. Nat Cell Biol 13: 132-141, 2011

26. Din FV, Valanciute A, Houde VP, Zibrova D, Green KA, Sakamoto K, Alessi DR and Dunlop MG: Aspirin inhibits mTOR signaling, activates AMP-activated protein kinase, and induces autophagy in colorectal cancer cells. Gastroenterology 142 1504-1515 e3, 2012.

27. Jin R, Gao Y,Zhang S, Teng F, Xu X, Aili A, Wang Y, Sun X, Pang X, Ge $Q$ and Zhang Y: Trx1/TrxR1 system regulates post-selected DP thymocytes survival by modulating ASK1-JNK/p38 MAPK activities. Immunol Cell Biol 93: 744-752, 2015.
28. Zhang M, Harashima N, Moritani T, Huang W and Harada M: The roles of ROS and caspases in TRAIL-induced apoptosis and necroptosis in human pancreatic cancer cells. PLoS One 10: e0127386, 2015.

29. Tsuchiya A, Kaku Y, Nakano $T$ and Nishizaki $T$ : Diarachidonoylphosphoethanolamine induces apoptosis of malignant pleural mesothelioma cells through a Trx/ASK1/p38 MAPK pathway. J Pharmacol Sci 129: 160-168, 2015.

30. Zhang X, Qin J, Zou J, Lv Z, Tan B, Shi J, Zhao Y, Ren H, Liu M, Qian M and Du B: Extracellular ADP facilitates monocyte recruitment in bacterial infection via ERK signaling. Cell Mol Immunol 15: 58-73, 2018.

31. Yokoi K, Kobayashi A, Motoyama H, Kitazawa M, Shimizu A, Notake T, Yokoyama T, Matsumura T, Takeoka M and Miyagawa SI: Survival pathway of cholangiocarcinoma via AKT/mTOR signaling to escape RAF/MEK/ERK pathway inhibition by sorafenib. Oncol Rep 39: 843-850, 2018.

32. An H and Harper JW: Systematic analysis of ribophagy in human cells reveals bystander flux during selective autophagy. Nat Cell Biol 20: 135-143, 2018.

33. Nagakannan P and Eftekharpour E: Differential redox sensitivity of cathepsin B and L holds the key to autophagy-apoptosis interplay after Thioredoxin reductase inhibition in nutritionally stressed SH-SY5Y cells. Free Radic Biol Med 108: 819-831, 2017.

34. Lin YX, Gao YJ, Wang Y, Qiao ZY, Fan G, Qiao SL, Zhang RX, Wang L and Wang H: pH-sensitive polymeric nanoparticles with gold(I) compound payloads synergistically induce cancer cell death through modulation of autophagy. Mol Pharm 12: 2869-2878, 2015.

35. Huang SY, Chien CC, Hseu RS, Huang VYJ, Chiang SY, Huang CJ, Chen SK, Tsai RY, Lin HT and Cheng YC: Ganoderma microsporum immunomodulatory protein induces apoptosis and potentiates mitomycin $\mathrm{C}$-induced apoptosis in urinary bladder urothelial carcinoma cells. J Cell Biochem 119 4592-4606, 2018.

36. Wang X, Dong H, Li Q, Li Y and Hong A: Thioredoxin induces Tregs to generate an immunotolerant tumor microenvironment in metastatic melanoma. Oncoimmunology 4: e1027471, 2015.

This work is licensed under a Creative Commons Attribution-NonCommercial-NoDerivatives 4.0 International (CC BY-NC-ND 4.0) License. 